\title{
POSSIBILITY OF INFERRING WATER QUALITY USING DC ELECTRICAL RESISTIVITY MEASUREMENTS : A CASE STUDY OF THE DUPI TILA AQUIFER IN BANGLADESH
}

\author{
DELWAR HOSSAIN \\ Department of Geological Sciences, Jahangirnagar University, Savar, Dhaka 1342, \\ Bangladesh
}

\begin{abstract}
A method of determining some parameters of water quality, namely calcium and hardness concentrations in the Dupi Tila sand aquifer in Bangladesh using vertical electrical sounding (VES) measurements is presented. The study site comprises an elevated land of the Madhupur Tract representing the Madhupur Clay Formation of the Pleistocene age. Using the relationships between formation water resistivity $\left(\mathrm{R}_{\mathrm{w}}\right)$ and calcium and hardness concentrations have allowed to relate the latter to formation resistivity $\left(\mathrm{R}_{\mathrm{o}}\right)$ as functions of porosity $(\Phi)$. The VES derived water quality parameter values seem to differ to some extent from that obtained from laboratory analysis. Provided VES data interpretation is well constrained, it can be a tool that might give some hints of the quality of water. The assumptions to be made to infer water quality from geoelectric sections are presented.
\end{abstract}

Key words: Vertical electrical sounding, Water quality inference, Dupi Tila aquifer Madhupur Tract

\section{INTRODUCTION}

Electrical resistivity surveys have long been employed in the investigations of shallow subsurface, including hydrogeological, geotechnical and environmental studies. It is most common to carry out vertical electrical sounding (VES), but resistivity profiling (electrical resistivity tomography (ERT)) is also applied in fields, including aquifer characterization and tracer test (Turesson 2006, Wilkinson et al. 2010, Arora and Ahmed 2011, Doetsch et al. 2011, McClymont et al. 2011), studying unsaturated zone (Andrews et al. 1995, Carrière et al. 2013), studying resources (Chambers et al. 2013, Longo et al. 2014), characterizing water leakage in dam (Al-Fares 2011), investigating complex subsurface geology (Griffiths and Barker 1993), among many others. VES surveys are conducted in, e.g., the area of the abandoned landfill (Khalil 2012), hydraulic parameters estimation (Perdomo et al. 2014), delineating saltwater and freshwater aquifers (Hodlur et al. 2006), investigating hydrogeology (Lenkey et al. 2005), characterizing water leakage in dam (Al-Fares 2011), studying saline water intrusion in coastal alluvial terrain (Choudhury et al. 2001). The VES technique used for investigating the change in 
resistivity with depth uses commonly a 4-elctrode configuration can only acquire a limited number of data points. Whereas, ERT is a survey technique used for investigating the change in resistivity both vertically and laterally based on the resistivity measurements by passing an electrical current along many different paths and measuring the associated voltages providing usually increased resolution of the subsurface.

The Dupi Tila aquifer is one of the most productive aquifers in Bangladesh. It provides water for several large cities, including Dhaka. This aquifer is overlain and underlain by the Madhupur Clay Formation and a second clay unit (Girujan Clay Formation?), respectively and is semi-confined in nature.

The water level of the aquifer is gradually going down every year due to overextraction and an excess pumping of groundwater (i.e., the annual withdrawal of groundwater is more than the annual recharge). The average rate of water level lowering is about $0.7 \mathrm{~m} / \mathrm{yr}$.

Borehole geophysical log data of the city of Dhaka have been studied by Majumder (1996), Hossain and Majumder (1998), and Hossain and Majumder (2000). Woobaid and Chowdhury (1998) investigated the surface resistivity measurements of Dhaka city to infer subsurface resistivity structure. The application of 2-D electrical imaging survey in hydrogeology for the Jahangirnagar University campus has been discussed by Hossain (2000) and in some geotechnical investigation of Madhupur clays by Kabir et al. (2011).

The economic value of the groundwater resource is dependent on the concentration of dissolved solids in groundwater (Hoekstra et al. 1992), and, fortunately, this concentration seems not to vary significantly in the Dupi Tila aquifer.

The objectives of this work were to determine using surface resistivity measurements the distribution of some water quality, namely calcium and hardness concentrations, in the Dupi Tila sand aquifer underlying the Madhupur Clay Formation in the Madhupur Tract in Bangladesh. The work on methodology which is going to be tested here can also be used for any type of quality inference. In fact, there is no geophysical alternative to that approach, since electrical resistivity is the only physical property highly influenced by dissolved solids in groundwater. There have been some works in Bangladesh related to the evaluation of water quality based on resistivity measurements. The act of deriving water quality from electrical resistivity requires isolating its influence on resistivity. The drinking water standards are, e.g., calcium $\left(\mathrm{Ca}^{++}\right)$concentration of less than $75 \mathrm{mg} / \mathrm{l}$, and hardness $\left(\mathrm{CaCO}_{3}\right)$ less than $500 \mathrm{mg} / \mathrm{l}$.

The elevated land of the Madhupur Tract represents the Madhupur Clay Formation of the Pleistocene age; and it is the oldest exposed rock of this region. It is 
unconformably underlain by the Dupi Tila Formation of late Pliocene age and unconformably overlain by the Holocene Alluvium. The stratigraphy of the Madhupur Tract has been discussed by Hossain (2000).

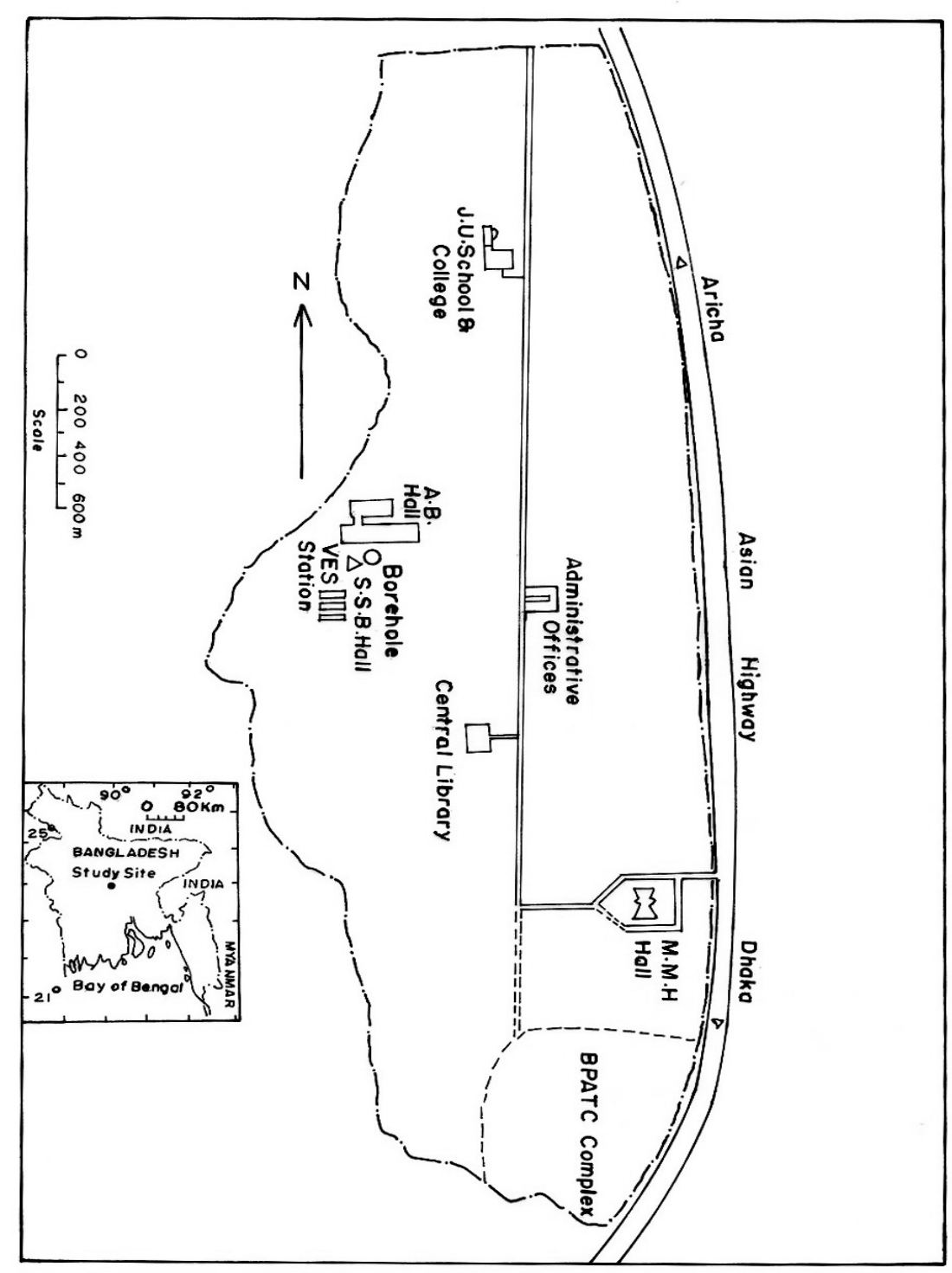

Fig. 1. Location of the Jahangirnagar University campus, the VES station and the borehole.

The study area comprises three hydrostratigraphic units down to the depth of $200 \mathrm{~m}$ : aquitard (Madhupur Clay Formation of Pleistocene age), aquifer (Dupi Tila Formation of late Pliocene age) and aquiclude (Girujan Clay Formation of middle Pliocene age?). 
The uppermost unit of the aquifer system - the aquitard - has an average thickness of about $10 \mathrm{~m}$, and consists of clay, silty clay, silt and sand. The aquifer underlying the aquitard is the lower unit of the aquifer system and has an average thickness of about 140 $\mathrm{m}$. The aquifer is separated into three major sections. The upper aquifer with average thickness of about $20 \mathrm{~m}$ is composed of very fine to fine sand. The middle aquifer with an average thickness of about $50 \mathrm{~m}$ is composed of fine to medium sand. The lowermost or main aquifer with thickness ranging from 15 to more than $125 \mathrm{~m}$ is composed of medium to coarse sand and occasional gravels at some places.

The potential recharge to the aquifer system is from rainfall and flooding. The water level is usually at depths 11-12 m below ground level (BGL) on the Jahangirnagar University campus. The aquifer is generally tapped for domestic water use using both shallow and deep tubewells or for irrigation purposes using deep tubewells (Hossain 2000).

\section{MATERIALS AND METHODS}

The hydrogeological data used in this paper have been collected from the Dhaka Water and Sewerage Authority (DWASA) and the Jahangirnagar University, Savar, Dhaka.
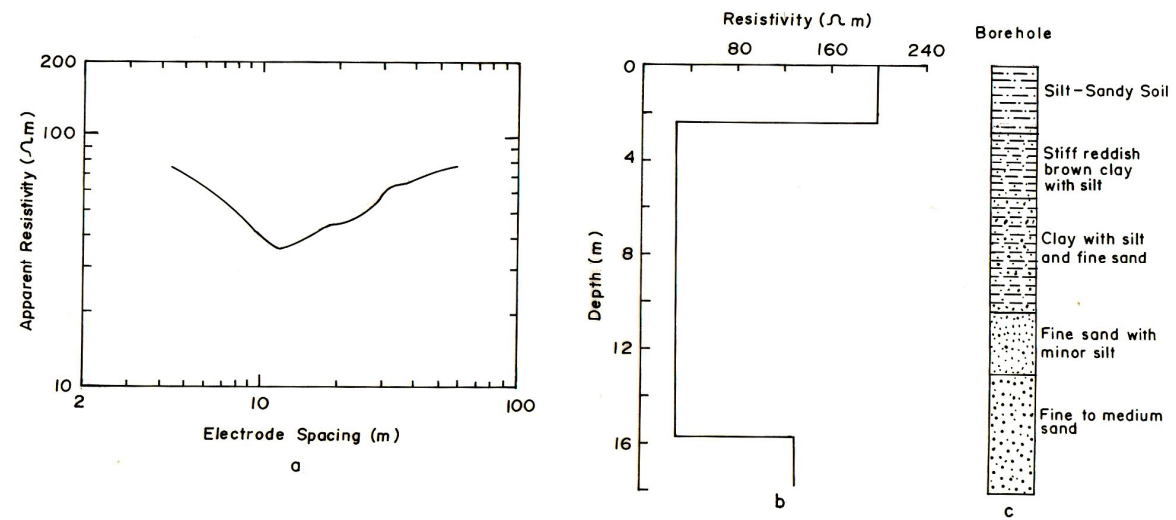

Fig. 2. Wenner resistivity sounding (a), geoelectric section derived from 1-D inversion (b) and borehole $\log (\mathrm{c})$.

The geoelectric section at a site within the Jahangirnagar University campus (Fig. 1) was determined by VES using a Wenner configuration. The VES data were collected using an IGIS DDR3 DC resistivity meter. The resistivity data were inverted using an inversion program called Schlum.

The general equations relating $R_{w}$ to calcium concentrations and $R_{w}$ to hardness concentrations were derived. The latter were then related to formation resistivity $R_{\mathrm{o}}$ as functions of porosity $\Phi$. 


\section{RESULTS AND DISCUSSION}

One measured apparent resistivity curve and the inverted 1-D geoelectric section, typical of those obtained throughout the Madhupur Tract, are shown in Fig. 2. The VES was interpreted to indicate three main subsurface layers. The sounding curve was interpreted as follows:

Layer 1- Top layer containing extremely compact dry, silty soil cover (with cricket ground pitch) (200 Ohm $\mathrm{m}$ ) between 0 and $2.4 \mathrm{~m}$ depth.

Layer 2- Madhupur clay (30 Ohm m) between 2.4 and $15.7 \mathrm{~m}$ depth.

Layer 3- Dupi Tila sand (133 Ohm m) below $15.7 \mathrm{~m}$ depth.

The interpretation seems to be constrained with respect to resistivity, but not to thickness. The top soil layer is slightly elevated and extremely compact and, as such, is characterized by high resistivity. Soundings at nearby stations (not shown here) also provide similar results, except the top resistive layer.

A VES measurement yields a geoelectric section, and to infer water quality from this section requires making certain assumptions and approximations. Steps made in correlating electrical resistivity to water quality is discussed as follows.

The VES derived geoelectric section has been compared to the lithologic log in a nearby hole (Fig. 2), they do not compare satisfactorily. In 1-D inversions, only distinct boundaries can be modeled and gradual transitions are not readily accommodated.

The resistivity of a water bearing rock $\left(R_{o}\right)$ is mainly a function of lithology, dissolved solids in groundwater, and porosity $(\Phi)$. Most rock forming minerals are essentially insulators and nearly all electrical current is carried either by free ions in pore water or by exchangeable ions associated with clay particles (Hoekstra et al. 1992).

An investigation into anisotropy shows that the Dupi Tila Sand Unit is more anisotropic (mostly due to change in lithology (clay lenses)) in comparison to the top and bottom units (Hossain and Majumder 1998). In most cases, the aquifer thickness obtainable from VES investigations seems to require no reduction, while in a few may require reduction of several per cent. The resistivity of the aquifer materials is mainly determined by lithology (sand size and clay content) and porosity.

Archie's law is used to express the relationship between formation resistivity $R_{0}$, fluid resistivity $\mathrm{R}_{\mathrm{w}}$ and porosity

$$
1 / \mathrm{F}=\mathrm{R}_{\mathrm{w}} / \mathrm{R}_{\mathrm{o}}=\Phi^{\mathrm{m}}
$$

where $\mathrm{F}=$ formation resistivity factor. The value of the empirically derived constant m can be accepted as 1.4 for the Dupi Tila Sand (Majumder 1996). 
$\mathrm{R}_{\mathrm{w}}$ is a function of the concentration of dissolved solids and ionic composition (Hoekstra et al. 1992). The correlation between $\mathrm{R}_{\mathrm{w}}$ and ion concentration is strong for major ions present within a particular water mass type, although $\mathrm{R}_{\mathrm{w}}$ is not a direct indicator of water quality. In this work, water quality is analysed in terms of hardness $(\mathrm{H})$ and calcium $(\mathrm{Ca})$ concentrations. Fig. 3 illustrates the relationships between $\mathrm{R}_{\mathrm{w}}$ and calcium concentration, and $\mathrm{R}_{\mathrm{w}}$ and hardness concentration for wells tapping the Dupi Tila sand aquifer underlying Dhaka city. The wells include DW1/9 (Saidabad), DW1/26 (Jatrabari-2), DW1/27 (Gopibagh), DW5/16 (Niketon), DW5/17 (Maddha Badda), DW5/18 (Banani), DW5/22 (Kuril Sewra), DW5/23 (Khilkhet Namapara), DW5/35 (Uttara-3), DW5/38 (Shahzadpur), DW5/39 (Kalachandpur), DW6/12 (Khilgaon), DW6/30 (Nayapara) and DW6/10 (Rajarbagh-2). The relationships appear to assume hyperbolic nature. Hardness is found to exhibit higher degree of correlation with $R_{w}$ in comparison to calcium ions.

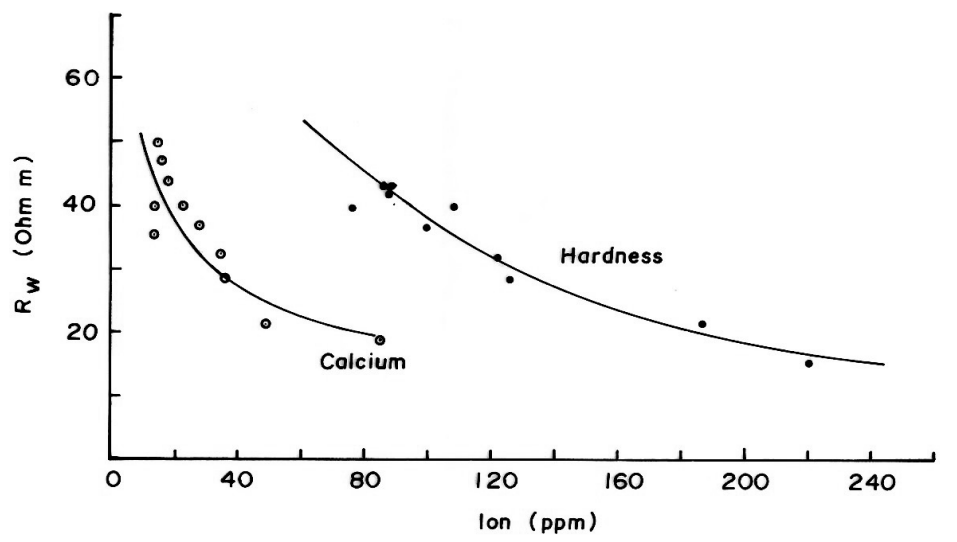

Fig. 3. Approximate relationship between ions and fluid resistivity $\left(\mathrm{R}_{\mathrm{w}}\right)$ for wells tapping the Dupi Tila aquifer.

A general equation relating $\mathrm{R}_{\mathrm{w}}(\Omega \mathrm{m})$ to hardness (ppm) for wells tapping the Dupi Tila aquifer may be expressed as:

$$
\mathrm{R}_{\mathrm{w}}=(3220 / \mathrm{H})+4
$$

Using this equation or Fig. 3, hardness can be determined from $R_{w}$.

By combining equations (1) and (2), hardness can be related to formation resistivity $\left(\mathrm{R}_{\mathrm{o}}\right)$ as a function of $\Phi$ as:

$$
\mathrm{R}_{\mathrm{o}}=[(3220 / \mathrm{H})+4] 1 / \Phi^{\mathrm{m}}
$$

This relation is shown in Fig. 4a. For Dupi Tila aquifer with an average $\Phi$ of $30 \%$, hardness less than $200 \mathrm{mg} / \mathrm{l}$ is expected when its formation resistivity is greater than $110 \mathrm{Ohm}$ $\mathrm{m}$. Hardness greater than $250 \mathrm{mg} / \mathrm{l}$ would be indicated by $\mathrm{R}_{\mathrm{o}}$ values less than $90 \mathrm{Ohm} \mathrm{m}$. 
A general equation relating $\mathrm{R}_{\mathrm{w}}(\mathrm{Ohm} \mathrm{m})$ to calcium concentration (ppm) for wells tapping the Dupi Tila aquifer may be expressed as:

$$
\mathrm{R}_{\mathrm{w}}=(330 / \mathrm{Ca})+17
$$

Using this equation or Fig. 3, Ca concentration can be determined from $R_{w}$.

By combining equations (1) and (4), Ca concentration can be related to formation resistivity as a function of porosity as:

$$
\mathrm{R}_{\mathrm{o}}=[(330 / \mathrm{Ca})+17] 1 / \Phi^{\mathrm{m}}
$$
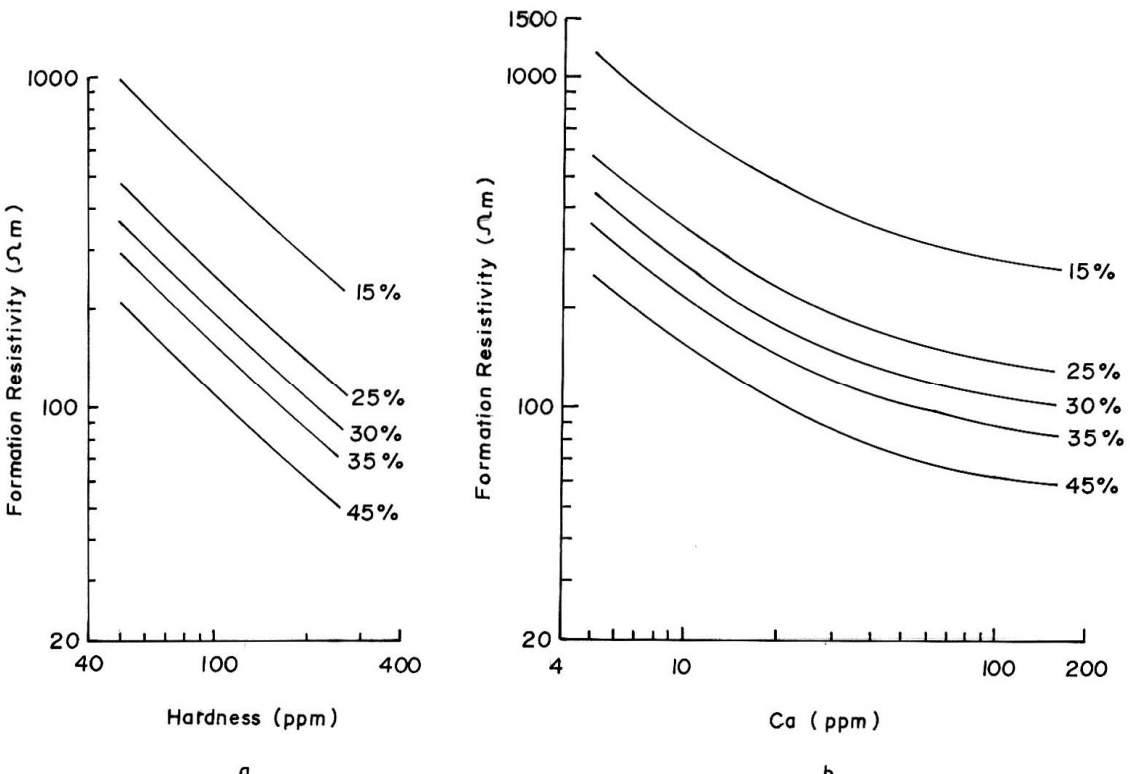

Fig. 4. Correlation between hardness and formation resistivity (a) and calcium concentration and formation resistivity (b) at several values of porosity.

This relation (Equation 5) is shown in Fig. 4b. For the Dupi Tila aquifer with an average porosity of $30 \%$, calcium concentrations less than $75 \mathrm{mg} / \mathrm{l}$ are expected when its formation resistivity is greater than $115 \mathrm{Ohm} \mathrm{m}$. Calcium concentrations greater than 150 $\mathrm{mg} / \mathrm{l}$ would be indicated by $\mathrm{R}_{\mathrm{o}}$ values less than $105 \mathrm{Ohm} \mathrm{m}$.

For the upper part of the Dupi Tila aquifer with $\Phi$ of about $42 \%$ and formation resistivity of about $133 \mathrm{Ohm} \mathrm{m}$, as obtained for the Jahangirnagar University site, hardness of about $88 \mathrm{mg} / \mathrm{l}$ is expected. Hydrochemical data from the nearest to the study site tubewell give the value of hardness as $72 \mathrm{mg} / \mathrm{l}$ indicating that the predicted value approximates to some extent the observed value. 
For the aquifer parameters cited above, calcium concentration of about $13.5 \mathrm{ppm}$ is expected. Hydrochemical data from the same tubewell give the value of $\mathrm{Ca}$ concentration as $9.5 \mathrm{ppm}$. This indicates that the VES derived Ca concentration differs from the one obtained from hydrochemical analysis.

Although the order of the two values compared is almost the same, both the VES derived concentration values appear to exceed the measured values. This could primarily be related to ambiguity in VES data interpretation.

Deriving water quality from a measured value of formation resistivity is possible only making certain assumptions. The following assumptions are to be made throughout the region where Dupi Tila aquifer is tapped.

(a) The relations between $\mathrm{R}_{0}$ and hardness concentration (Fig. 4a) and $\mathrm{R}_{\mathrm{o}}$ and Ca concentration (Fig. 4b) are valid for the whole region where the Dupi Tila aquifer is tapped.

(b) The porosity of the aquifer materials, as computed from geophysical logs, ranges from $16 \%$ to $42 \%$ with an average value of about $30 \%$ (Hossain and Majumder 2000). The latter can be used for determining water quality for some site unless porosity-depth distribution is available. If there is scope of using the latter, the inference would obviously be more precise.

(c) For the aquifer, the $\mathrm{R}_{\mathrm{o}}$ values are influenced by changes in lithology (clay content), porosity, and dissolved solids. This precluded inferring some interpretations about water quality, s.a., hardness and calcium concentrations, in the aquifer.

\section{CONCLUSIONS}

Provided there are simple structural situations and insignificant near-surface resistivity variations as well as VES data interpretation is well constrained, the Dupi Tila aquifer can be investigated using VES. Certain assumptions regarding lithology, porosity, and ionic composition need to be made while inferring water quality from geoelectric section. Hardness is found to exhibit higher degree of correlation with $\mathrm{R}_{\mathrm{w}}$ in comparison to calcium ions. For the Dupi Tila aquifer with porosity of $30 \%$, calcium concentrations greater than $150 \mathrm{mg} / \mathrm{l}$ would be indicated by formation resistivity values less than 105 Ohm $\mathrm{m}$, while hardness greater than $250 \mathrm{mg} / \mathrm{l}$ by formation resistivity values less than 90 $\mathrm{Ohm} \mathrm{m}$. The values of these parameters derived geophysically differ from that measured at the laboratory that could principally be related to nonuniqueness of VES data interpretation. If the VES data interpretation is well constrained, one may expect more accurate interpretation of water quality. The VES derived geoelectric sections on the 
Jahangirnagar University campus revealed comparable resistivity values for the aquifer indicating simplicity of approximately inferring water quality and possibility of using the same relationships throughout the tract. The methodology used here can be extended to evaluating other types of water quality.

Geoelectric methods may offer a quick and cost-effective means of approximately deriving water quality information that is useful whenever laboratory testing is inaccessible.

\section{ACKNOWLEDGEMENTS}

The present work presents a study conducted by the author from grant by the Jahangirnagar University authority. The author sincerely acknowledges this and all other research and logistic support provided by the University.

\section{REFERENCES}

Al-fares, W. 2011. Contribution of the geophysical methods in characterizing the water leakage in Afamia B dam, Syria. J. Appl. Geop. 75: 464-471.

Andrews, R. J., R. D. Barker and M. H. Loke. 1995. The application of electrical tomography in the study of the unsaturated zone in Chalk at three sites in Cambridgeshire, United Kingdom. Hydrog. J. 3: 17-31.

Arora, T. and S. Ahmed. 2011. Characterization of recharge through complex vadose zone of a granitic aquifer by time-lapse electrical resistivity tomography. J. Appl. Geop. 73: 35-44.

Carrière, S. D., K. Chalikakis, G. Sénéchal, C. Danquigny and C. Emblanch. 2013. Combining electrical resistivity tomography and ground penetrating radar to study geological structuring of karst unsaturated zone. J. Appl. Geop. 94: 31-41.

Chambers, J. E., P. B. Wilkinson, S. Penn, P. I. Meldrum, O. Kuras, M. H. Loke and D. A, Gunn. 2013. River terrace sand and gravel deposit reserve estimation using three-dimensional electrical resistivity tomography for bedrock surface detection. J. Appl. Geop. 93: 25-32.

Choudhury, K., D. K. Saha and P. Chakraborty. 2001. Geophysical study for saline water intrusion in a coastal alluvial terrain. J. Appl. Geop. 46: 189-200.

Doetsch, J., N. Linde, M. Pessognelli, A. G. Green and T. Günther. 2011. Constraining 3-D electrical resistance tomography with GPR reflection data for improved aquifer characterization. J. Appl. Geop. doi:10.1016/j.jappgeo.2011.04.008.

Griffiths, D. H. and R. D. Barker. 1993. Two-dimensional resistivity imaging and modelling in areas of complex geology. J. Appl. Geop. 29: 211-226.

Hodlur, G. K., R. Dhakate and R. Andrade. 2006. Correlation of vertical electrical sounding and borehole-log data for delineation of saltwater and freshwater aquifers. Geop. 71(1): G11-G20.

Hoekstra, P., J. Hild and D. Toth. 1992. Time domain electromagnetic measurements to determine water quality in the Floridan Aquifer. SAGEEP (Bell R. S. (ed.)) 1: 111-127.

Hossain, D. 2000. 2-D electrical imaging survey in hydrogeology. The Bangladesh J. Sc. Res. 18(1):57-66.

Hossain, D. and R. K. Majumder. 1998. On the application of vertical electrical sounding in the eastern part of Dhaka city, Bangladesh. Bangladesh Geosc. J. 4: 33-42. 
Hossain, D. and R. K. Majumder. 2000. Hydrogeological investigations of the eastern part of Dhaka city using geophysical well logging. J. Geol. Soc. India 56: 161-168.

Kabir, A.S.M.S., D. Hossain and R. Abdullah. 2011. 2-D electrical imaging in some geotechnical investigation of Madhupur clays, Bangladesh. J. Geol. Soc. India 77: 73-81.

Khalil, M. H. 2012. Magnetic, geo-electric, and groundwater and soil quality analysis over a landfill from a lead smelter, Cairo, Egypt. J. Appl. Geop. 86: 146-159.

Lenkey, L., Z. Hamori and P. Mihalffy. 2005. Investigating the hydrogeology of a water-supply area using direct-current vertical electrical soundings. Geop. 70(4): h11-h19.

Longo, V., V. Testone, G. Oggiano and A. Testa. 2014. Prospecting for clay minerals within volcanic successions: application of electrical resistivity tomography to characterise bentonite deposits in Northern Sardinia (Italy). J. Appl. Geop. 111: 21-32.

Majumder, R. K. 1996. Hydrogeological investigations of the eastern part of Dhaka City using geophysical well logging. M.Sc. Thesis, Dept. of Geological Sciences, Jahangirnagar University, Savar, Dhaka. pp. 182.

Mcclymont, A.F., J. W. Roy, M. Hayashi, L. R. Bentley, H. Maurer and G. Langston. 2011. Investigating groundwater flow paths within proglacial moraine using multiple geophysical methods. J. Hydrol. 399: 57-69.

Perdomo, S.,J. E. Ainchil and E. Kruse. 2014. Hydraulic parameters estimation from well logging resistivity and geoelectrical measurements. J. Appl. Geop. 105: 50-58.

Turesson, A. 2006. Water content and porosity estimated from ground-penetrating radar and resistivity. J. Appl. Geop. 58: 99-111.

Wilkinson, P.B., P. I. Meldrum, O. Kuras, J. E. Chambers, S. J. Holyoake and R. D. Ogilvy. 2010. High-resolution electrical resistivity tomography monitoring of a tracer test in a confined aquifer. J. Appl. Geop. 70: 268-276.

Woobaid Ullah, A.S.M. and S. U. Chowdhury. 1998. Subsurface resistivity characteristics of Dhaka City. J. Bangladesh Acad. Sci. 22(2): 211-216.

(Received revised manuscript on 15 April, 2016) 